\title{
On the Role of Worldliness in our Understanding of Being
}

\author{
Xiao-li YAN \\ School of Foreign Languages, Henan Institute of Engineering, Zhengzhou, China \\ 52453091@163.com
}

Keywords: Worldhood or worldliness, Understanding, Being, Heidegger, Understanding of being .

\begin{abstract}
The term of worldhood or worldliness means that "the Being of that ontical condition which makes it possible for entities within-the-world to be discovered at all - the worldhood of the world" (BT, 121). That is, the worldhood is like a framework or conceptual scheme which overarches or underlies our practical or empirical world. The worldhood is being in terms of an intelligible structure which is made up of our understanding of being and is accordingly shaped as such in that being-structure.
\end{abstract}

\section{Introduction}

The term of worldhood or worldliness means that "the Being of that ontical condition which makes it possible for entities within-the-world to be discovered at all - the worldhood of the world" (BT, 121). That is, the worldhood is like a framework or conceptual scheme which overarches or underlies our practical or empirical world. The worldhood is being in terms of an intelligible structure which is made up of our understanding of being and is accordingly shaped as such in that being-structure. Yet Dasein will never come to the end of its understanding of being as long as it exists. As long as Dasein exists it always "comports itself understandingly to the Being" (BT, 78). As mentioned previously, the essence of Dasein lies in its existence, and existence means potentiality-for-being, means to be, and being-possible. At the same time, it also means "Being-in". "Being-in is thus the formal existential expression for the Being of Dasein, which has Being-in-the-world as its essential state" (BT, 80). "Furthermore, Dasein is an entity which in each case I myself am. Mineness belongs to any existent Dasein, and belongs to it as the condition which makes authenticity and inauthenticity possible" (BT, 78). Therefore, Dasein's understanding of being is not only constitutive and constituting along with its existence but also has its particular personalities or individuations. That is, an individual Dasein's understanding of being only belongs to this Dasein but not others. Mineness is always indelibly there in the act of an understanding of being, even though such an understanding of being is only a kind of repetition.

\section{The Mineness of Understanding of Being}

Although this understanding of being is constitutive and constituting as well as individualized in terms of mineness, it nevertheless possesses the status of a holistic structure not at a particular moment for any Dasein. As we have mentioned, for Dasein there is always already a somehow understanding of being which illumines its comportments towards entities within the world and this kind of understanding of being, in our discussion, is somewhat like a light which opens a world and constitutes the structure of being-in-the-world. According to Heidegger, "Being-in-the-world" is a compound expression that "indicates in the very way we have 
coined it, that it stands for a unitary phenomenon. This primary datum must be seen as a whole. But while Being-in-the-world cannot be broken up into contents which may be pieced together, this does not prevent it from having several constitutive items in its structure" (BT, 78). This means that the world of this expression is a world which has been lit up by being or understanding of being that lies in nowhere but in the world. So the world is not a world whose contents are pieced together, on the contrary, they are arranged and formed according to being or understanding of being. Being is an openness which opens a terrain as its world; therefore, the world is a clearing which is cleared by its being. Here, "being" and "world" are inseparable; they come to together and unite into one. In an inter-reliable and co-existing relationship, being weaves itself in the world and constitutes a holistic relational structure "in which Dasein always already finds itself' (HW, 28).

Obviously the world in this compound expression "Being-in-the-world" does not refer to our surrounding, environment, which are considered objectively, or the world at which scientists aim their gaze. "It is closer to what might be called our personal world. World is not the whole of all beings but the whole in which the human being always finds himself already immersed, surrounded by its manifestness as revealed through an always pregrasping, encompassing understanding" (Palmer, 1969:132). So, this world is a world which is always already pre-given to Dasein, and also an a priori perfect (for the expression of "always already" indicates) world which functions as a holistic relational structure about Dasein. This holistic relational structure, as has been discussed, is obviously woven by understanding of being. On the other hand, since "understanding of being is itself a definite characteristic of Dasein's being" (BT, 32) and "Dasein is an entity which, in its very Being, comports itself understandingly towards that Being" (BT, 78), therefore Dasein is such an understanding of being, and vice versa. This is the deep meaning of our expression "Understanding as a Holistic Structure". Not only that, these two quotations once again proves that "an understanding" of being is the "being" of an understanding. That is to say, the two constitutive items on the sides of "of' can be exchanged equally in their use.

With this in mind, when Heidegger says 'Dasein's Being ... must be seen and understood $a$ priori as grounded upon that state of Being which we have called 'Being-in-the-world"' (BT, 78), we can make a replacement of "understanding" for "being" by saying, "Dasein's understanding ... must be seen and understood a priori as grounded upon that state of Understanding which we call understanding-in-the-world". Functioning as being, understanding also orders and arranges itself a world, demarcating the boundaries between what is understood and what is not. Like Being, what is lighted up by understanding comes into our view which constitutes a holistic structure of understanding as the whole world around us. Obviously, this holistic structure of understanding is the most primordial or original structure in which the human being or Dasein always finds himself. Only because it is the most original, is it the ground upon which the derivative, empirical understandings are founded. Here the attributive words like the most basic, primordial and original have won the status of ontology, while the derivative and empirical are used in terms of ontics. According to Heidegger's ontological difference, the former always founds the latter. Therefore, the original holistic structure of understanding always founds its reification in the various ontical and practical understandings. 


\section{The Ontological Understanding}

Yet one point about the conception of ontological understanding must be made clear: even though the ontological understanding is a holistic relational structure that functions as the grounding for the various empirical understandings, it nevertheless does not necessarily mean that it keep changeless all the time while Dasein exists. Quite the contrary, it always lies in a state of interactions and intermodifications with its founded or derivative empirical understandings. It will adjust itself to be agreeable with the ontical situations, and only in this way can its holistic character be maintained. In fact, the most basic human existence of being-in-the-world essentially requires that it must be the outcome of interactions and intermodifications, because what is ready-to-hand is never separable from what is present-at-hand, and only through such interplays and intermodifications between them, can the being of readiness-to-hand be the such-and-such. And only in this manner, too, can the proper sense of "holistic" be done to its full right. This opinion is echoed by Gadamer's explanation on how we can "go to the things themselves" in an interpretation of literature (TM, 232-238).

According to our above discussions, Dasein's definite character of "to be" or "potentiality-for-being" does not allow itself to hold the holistic structure of its primary understanding of being changeless all the time. Furthermore, Heidegger's ontological difference, that is, the distinction between being and beings, and his phenomenological methodology about the investigation of the question of the meaning of being, both require Heidegger to set up not only a "founding relationship between ontological structures and their ontic embodiments" (HW, 18), but also to distinguish "the ontic and the ontological by analogy with the empirical/transcendental dichotomy, that is, his wish to have recourse to a founding relation (constituting/constituted)" (ibid). Accordingly, the holistic structure which has been set up by the primary understanding of being must be adjusted by its derivative ontical understandings. Taking into account Heidegger's later anatomies of Dasein in terms of historicality and facticity in BT, Dasein's pre-given world or the holistic structure which is set up by the primary understanding of being, that is, being-in-the-world, or the understanding of being-in-the-world, has more reasons to adjust itself in accordance with the empirical/ontical understandings.In short, understanding as a holistic structure is a primary relational wholeness of a world or the worldhood of the world which is co-originally established by an understanding of being. Such a structure has been lighted up by an understanding of being; therefore it is also a symbolically structured world or system in itself. Understanding is like a magical thread that interweaves an understood relational network, or is like an intelligible light which discloses a terrain which understands. So, the original holistic structure of understanding on the one hand provides the human being who understands with a freedom in his already understood realm; while on the other hand, it also constrains the human being who understands within the boundaries of understanding. However, it is the freedom and the constraint that lead and guide the human being in his moving about. That is to say, the function of guidance of understanding is inherent in itself.

\section{Understanding as a Guidance}

In Being and Time (BT), Heidegger time and again observes that "Dasein is an entity which, in its very Being, comports itself understandingly towards that Being" (BT, 78) and "Dasein is always somehow directed and on its way; standing and waiting are only limiting cases of this 
directional 'on-its-way'" (BT, 110). Here, one may ask: "Where does this directional 'on-its-way' find its way?" Based on what has been discussed in the foregoing parts and particularly the quotations mentioned just now, we can easily answer this question: this directional 'on-its-way' will ultimately find its way into an understanding of being. Understanding is an illuminating element which "makes up the constitution of the being of Dasein, from which there first arise the various ways of knowing the world, and hence any of the particular regional ontologies" (HW,15). That is to say, the various ways of "knowing" are just the derivative modes of understanding (ibid). Now that an understanding of being is the ultimate source of the directional comporting as well as the most fundamental ground by which our actions can be far frombeing free-floating, blindness and undirectedness, therefore it must be capable of offering a guidance.

\section{Conclusion}

According to Heidegger, our essential character is our existence which is fundamentally characterized by our being-in-the-world, and the term "the world" in the compound expression only belongs to our human beings because it is co-originally set up with an understanding of being of entities within the world. In Heidegger's words: "What can be meant by describing 'the world' as a phenomenon? It means to let us see what shows itself in 'entities' within the world" (BT, 91; italics added). However, how is it possible that 'the world" can "let us see what shows itself in 'entities' within the world"? As far as what has been made clear about an understanding, we know that an understanding is the first ray of light which arises in a relational network to illumine a human being who understands a world, and we also know that the human being who understands exists in his basic state of being-in-the-world, so the answer to that question must be necessarily grounded upon an understanding which is obviously equiprimordial with "the world", for "the world" is nothing more than "what shows itself in "entities", , and the entities have already been disclo sed by an understanding in advance. To combine the upshots, we can simply claim that "It (the world) means to let us see what shows itself in 'entities' within the world" is equivalent to "It (the world) means to let us see what an understanding shows itself in 'entities' within the world". Therefore, in Heidegger's mind, an understanding always means an understanding of a phenomenological world (the world), and a phenomenological world (the world) always means a world of understanding or a world which understands.

\section{References}

[1] Heidegger, Martin. Being and Time. John Macquarrie \& Edward Robinson (trans.) China Social Sciences Publishing House Chengchengh Books Ltd., 1999.

[2] Norris, Christopher. Deconstruction: Theory and Practice. London and New York: Methuen Co. Ltd., 1982.

[3] Palmer, Richard E. Hermeneutics -- Interpretation Theory in Schleiermacher, Dilthey, Heidegger, and Gadamer. Evanston: Northwestern University Press, 1969. 